\title{
PERANCANGAN PROSES MENETAPKAN RISIKO DAN PELUANG BERDASARKAN ISO 9001:2015 KLAUSUL 6.1 DENGAN PENDEKATAN ISO 31000:2009 MENGGUNAKAN METODE BUSINESS PROCESS IMPROVEMENT DI CV XYZ
}

\author{
${ }^{1}$ Tri Imam Wicaksono, ${ }^{2}$ Agus Alex Yanuar, ${ }^{3}$ Heriyono Lalu \\ 1,2,3Program Studi Teknik Industri, Fakultas Rekayasa Industri, Telkom University \\ 1triimamwicaksono@gmail.com, ${ }^{2}$ axytifri@telkomuniversity.ac.id, ${ }^{3}$ heriyonolalu@telkomuniversity.ac.id
}

\begin{abstract}
Abstrak-Jumlah industri kecil di Indonesia sangat banyak, khususnya provinsi Jawa Barat, yaitu 58.359 perusahaan. Dengan banyaknya perusahaan kecil, maka $C V X Y Z$ harus bisa bersaing dengan perusahaan sejenisnya, salah satunya dengan menjaga kualitas produk yang dihasilkan dengan cara menerapkan sistem manajemen mutu. ISO 9001:2015 merupakan salah satu standar internasional mengenai sistem manajemen mutu yang bisa diimplementasikan oleh perusahaan sebagai salah satu strategi untuk bisa bersaing.Selain itu pada ISO 9001:2015 terdapat persyaratan agar perusahaan melakukan manajemen risiko disetiap prosesnya.Untuk mendukung perusahaan melakukan manajemen risiko, ISO memiliki seri 31000:2009 yang bisa digunakan oleh perusahaan. Oleh karena itu, penelitian ini berfokus pada klausul 6.1(menetapkan risiko dan peluang) ISO 9001:2015 dan pendekatan ISO 31000:2009 klausul 5 (manajemen risiko). Kemudian kondisi aktual perusahaan akan dibandingkan dengan requirement ISO 9001:2015 klausul 6.1, requirement ISO 31000:2009, dan requirement teori manajemen risiko sehingga dihasilkan suatu gap. Selanjutnya dilakukan perancangan proses menetapkan risiko dan peluang berdasarkan hasil gap yang telah didapatkan. Kemudian rancangan proses yang telah dibuat akan dilakukan perbaikan dengan metode business process improvement pada tahap apply improvement technique. Hasil dari rancangan proses menetapakan risiko dan peluang akan didokumentasikan dalam bentuk standard operating procedure. Selain itu untuk memudahkan perusahaan dalam melakukan pendokumentasian disetiap aktivitasnya, maka dibuat form berbasis web aplikasi dengan software Joget Workflow agar data yang diinput dapat tersimpan secara teratur.
\end{abstract}

Kata kunci: business process improvement, standard operating procedure, manajemen risiko, ISO 9001:2015, ISO 31000:2009, Joget Workflow

\section{PENDAHULUAN}

Berdasarakan hasil survey Badan Pusat Statistik pada tahun 2016, terdapat 58.359 perusahaan industri kecil di provinsi Jawa Barat [1]. Dengan banyaknya jumlah tersebut maka perusahaan harus bisa melakukan persaingan salah satunya dengan memperbaiki sistem manajemen mutu perusahaan sehingga produk yang dihasilkan memiliki kualitas yang baik [2].

ISO 9001 merupakan salah satu standar internasional mengenai sistem manajemen mutu [3].Sistem manajemen mutu digunakan agar perusahaan melakukan perbaikan berkelanjutan, sehingga menghasilkan proses perusahaan yang baik [4] [5].Pada tahun 2015 ISO menerbitkan seri barunya yaitu ISO 9001:2015. Terdapat pembaharuan pada ISO 9001:2015 salah satunya yaitu $I S O$ mempertimbangkan risiko pada setiap proses [6]. Pertimbangan risiko pada proses merupakan suatu hal yang penting, karena suatu proses dalam perusahaan pasti mempunyai beberapa risiko yang akan mengganggu kelangsungan proses atau tujuan dari proses tersebut. Dengan melakukan pengelolaan risiko yang baik, perusahaan dapat mengurangi dampak dari risiko yang akan timbul [7]. Perusahaan memerlukan proses menetapkan risiko dan peluang sebagai pengelolaan risiko di perusahaan. Persyaratan yang harus dipenuhi pada proses tindakan untuk menangani risiko dan peluang, yaitu terdapat pada ISO 9001:2015 klausul 6.1, selain itu untuk mendukung proses tersebut dibutuhkan pendekatan melalui ISO 31000:2009 serta teori manajemen risiko.

CV XYZ merupakan salah satu perusahaan manufaktur di Bandung penghasil produk plastik dan besi.CV XYZ memiliki beberapa mitra salah satunya yaitu PT.Showa Mfg.PT.Showa Mfg merupakan mitra perusahaan yang meminta perusahaan segera mengimplementasikan ISO 9001:2015.Hal itu merupakan salah satu syarat agar CV XYZ masih bisa melakukan kerja sama dengan PT.Showa Mfg. Kondisi aktual perusahaan saat ini yaitu belum memenuhi persyaratan ISO 9001:2015, salah satunya adalah klausul 6.1 mengenai penetapan risiko dan peluang di seluruh proses perusahaan. Hal 
itu merupakan bagian penting dari persyaratan, karena dengan mempertimbangkan risiko pada setiap proses, perusahaan bisa mengelola risiko agar tujuan proses dapat tercapai. Selain itu perusahaan belum mendokumentasikan dengan baik mengenai pengelolaan risikonya dan tidak terdapat suatu prosedur untuk melakukan manajemen risiko di perusahaan sehingga proses manajemen risiko perusahaan tidak terkelola dengan baik.

\section{STUDI LITERATUR}

\section{A. Sistem Mananjemen Mutu}

ISO 9001 merupakan sebuah standard internasional yang dikeluarkan oleh International Organization for Standardization mengenai sistem manajemen mutu. ISO 9001:2015 adalah versi terbaru dari standard mengenai sistem manajemen mutu yang dikeluarkan oleh International Organization for Standardization. ISO 9001:2015 mempunyai beberapa perubahan pada prinsipnya berdasarkan sistem manajemen mutu.ISO 9001:2015 menggunakan konsep risk based thinkin, yaitu mengidentifikasi risiko dalam suatu organisasi sehingga dapat terhindar dari berbagai risiko dalam menjalankan prosesnya. Selain itu pada ISO 9001:2015 menerapkan High Level Structure (HLS) untuk perubahan strukturnya sehingga terdapat 10 klausul pada ISO 9001:2015[6].

\section{B. Perancangan Proses}

ISO 9001:2015 memberikan himbauan kepada perusahaan agar perusahaan harus menentukan proses yang diperlukan bagi sistem manajemen mutu dan penerapannya diseluruh perusahaan.Terdapat ketentuan-ketentuan dalam merancang suatu proses menurut klausul 4.4.1 ISO 9001:2015, yaitu [6]:

1. Organisasi harus menetapkan masukan yang diperlukan dan keluaran yang diharapkan dari proses

2. Menetapkan urutan dan interaksi proses

3. Menetapkan dan menerapkan kriteria, metode (termasuk pengukuran dan indikator kinerja terkait) yang diperlukan untuk memastikan operasi, dan kendali proses yang efektif

4. Menetapkan sumber daya yang diperlukan dan memastikan ketersediaan.

5. Penunjukan tanggung jawab dan wewenang untuk proses tersebut.

6. Menangani risiko dan peluang sesuai dengan persyaratan dari klausul 6.1, merencanakan dan menerapkan tindakan yang tepat untuk mengatasinya.

7. Mengevaluasi metode untuk memantau, mengukur, bila sesuai, dan mengevaluasi proses dan, jika diperlukan, perubahan proses untuk mastikan hal tersebut mencapai hasil yang dimaksud.

8. Meningkatkan proses dan sistem manajemen mutu.

\section{Manajemen risiko}

Manajemen risiko adalah proses yang bertujuan untuk membantu organisasi memahami, mengevaluasi, dan mengambil menetapkan semua risiko dengan maksud untuk meningkatkan probabilitas keberhasilan dan mengurangi kemungkinan kegagalan.Untuk melakukan pengelolaan risiko perusahaan,terdapat sebuah proses manajemen risiko berdasarkan ISO 31000:2009 yaitu salah satunya yaitu risk assessement, dalam risk assessment terdapat beberapa tahap proses yaitu identifikasi risiko, analisis risiko,dan evaluasi risiko [8]. Selain menggunakan ISO 31000:2009 terdapat juga proses manajemen risiko yang disebut $7 \mathrm{R}$ dan $4 \mathrm{~T}$, yaitu recognition of risk untuk mengetahui atau mengidentifikasi risiko yang ada di setiap proses; ranking of risks merupakan langkah untuk melakukan pengurutan terhadap risiko yang akan dilakukan penanganan; responding to risks merupakan penanganan terhadap risiko dan terdapat empat kategori(tolerate,treat,transfer,terminate); resourcing controls merupakan pengalokasian sumber daya manusia untuk melakukan kontrol terhadap penanganan yang telah diberikan; reaction planning merupakan fase pemulihan perusahaan terhadap risiko yang telah terjadi ; reporting on risk merupakan laporan yang dibuat sebagai dokumentasi perusahaan mengenai manajemen risiko; dan reviewing sebagai tinjauan terhadap sistem manajemen risiko perusahaan [9].

\section{Business Process Improvement}

Business Process Improvement (BPI) merupakan sebuah metode yang mendesain ulang dari proses bisnis eksisting untuk mencapai sebuah peningkatan yang signifikan.Metode BPI yang digunakan pada penelitian ini yaitu tahap apply improvement technique. Apply improvement technique merupakan tahap untuk memperbaiki proses.Terdapat enam metode untuk memperbaiki proses, yaitu [10]:

1. Eliminating bureaucracy

Menghilangkan kegiatan yang bersifat administratif dan penggunaan kertas yang tidak diperlukan.

2. Evaluating value-added activities Mengevaluasi setiap aktivitas dalam proses untuk menentukan aktivitas yang mempunyai nilai tambah dan yang tidak.

3. Eliminating duplication and redundancy Menghilangkan aktivitas yang sama pada suatu bagian proses yang berbeda.

4. Simplifying the process, report, and forms Mengurangi kompleksitas suatu proses, laporan dan form yang digunakan.

5. Reducing cycle time Menentukan cara untuk mengurangi waktu siklus.

6. Applying automation tools Menerapkan peralatan otomatis pada proses,seperti komputer

Selain itu terdapat tiga objektif pada Business Process Improvement $(B P I)$, yaitu [10]:

1. Membuat proses menjadi lebih efektif agar hasil prosesnya sesuai dengan kemauan pelanggan

2. Membuat proses menjadi lebih efisien dengan meminimasi penggunaan sumber daya

3. Membuat proses menjadi adaptif sehingga dapat berubah mengikuti permintaan pelanggan 


\section{METODOLOGI PENELITIAN}

A. Model Konseptual

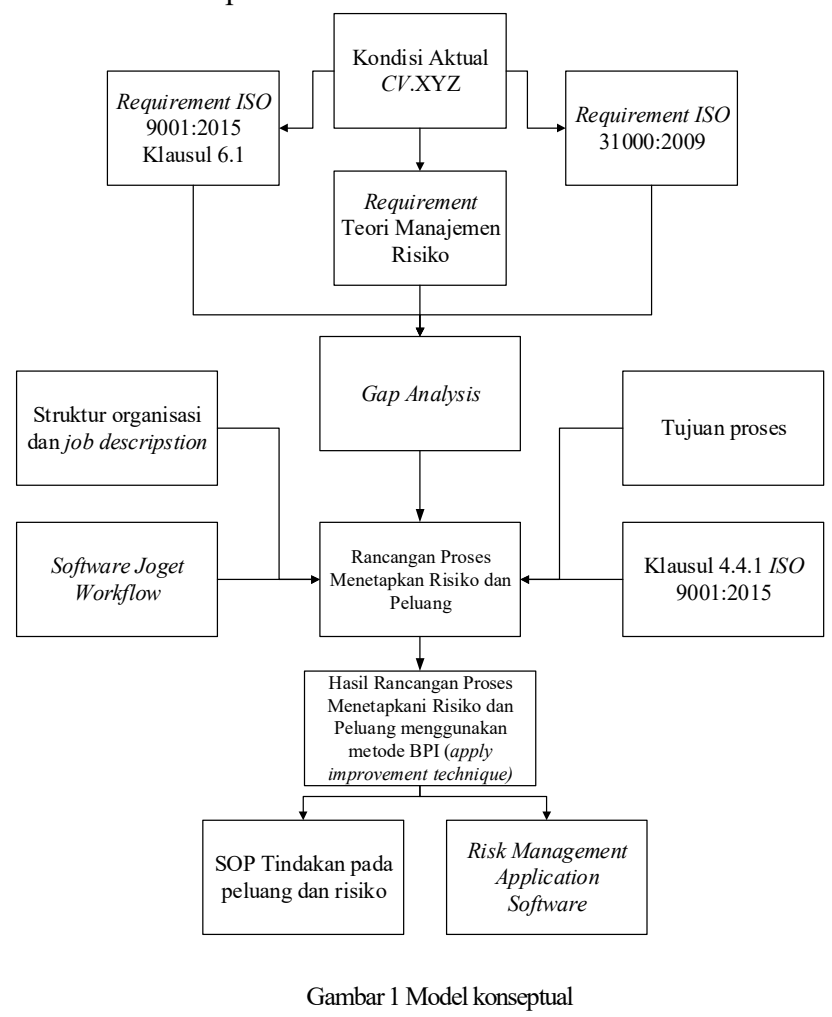

Pada Gambar 1 merupakan tahapan dalam melakukan penelitian ini untuk merancang proses menetapkan risiko dan peluang berdasarkan ISO 9001:2009 klausul 6.1 menggunakan metode business process improvement. Pada tahap awal yaitu melakukan studi lapangan dan juga studi literatur, untuk studi lapangan pada penelitian ini yaitu melihat kondisi aktual pada CV XYZ. Kondisi aktual merupakan kondisi yang sudah ada pada CV XYZ terkait menetapkan risiko dan peluang, kemudian kondisi aktual dibandingkan dengan requirement ISO 9001:2015 klausul 6.1, requirement ISO 31000:2009, dan requirement teori manajemen risiko sehingga didapatkan hasil gap dengan kondisi aktual.Kemudian rancangan proses bisnis menetapkan risiko dan peluang mempertimbangkan beberapa hal, yaitu struktur organisasi dan job description sebagai penentu penanggung jawab pada setiap aktivitas di proses tersebut, hasil gap analisis sebagai usulan untuk prosesnya, dan klausul 4.4.1 ISO 9001:2015 sebagai acuan dalam merancang proses sesuai dengan standar internasional.

Dari hasil perancangan proses yang telah dibuat, maka dilakukan apply improvement technique pada rancangan proses tersebut. Apply improvement technique merupakan salah satu tahapan pada metode business process improvement yaitu untuk memperbaiki proses atau aktivitas menjadi lebih efisien. Setelah dilakukan perbaikan pada proses menetapkan risiko dan peluang, maka proses tersebut didokumentasikan berupa standard operating procedure yang telah sesuai dengan requirement. Selain itu terdapat hasil rancangan software risk management application untuk mendukung proses menetapkan risiko dan peluang.

\section{HASIL DAN ANALISIS}

\section{A. Requirement Menetapkan Risiko dan Peluang}

Pada penelitian ini requirement mengenai manajemen risiko, yaitu ISO 9001:2015 klausul 6.1, ISO 31000:2009, dan teori manajemen risiko diintegrasikan dengan mengelompokkan klausul yang serupa dan membuat klausul yang baru jika tidak bisa dikelompokkan.Berikut ini merupakan penjabaran dari persyaratan ISO 9001:2015 klausul 6.1, ISO 31000:2009, dan teori manajemen risiko yang telah digabungkan:

1. Sub Klausul 6.1.1 Tindakan Untuk Menetapkan Risiko dan Peluang

Dalam mengembangkan sistem manajemen mutu, organisasi harus mempertimbangkan isu-isu internal dan eksternal serta menetapkan risiko dan peluang untuk :

a. Menjamin penerapan sistem manajemen mutu mencapai target yang diinginkan

b. Meningkatkan dampak yang diharapkan

c. Mencegah atau mengurangi dampak yang tidak diinginkan,

d. Mencapai perbaikan kinerja yang berkelanjutan

2. Sub Klausul 6.1.2 Tindakan Untuk Menetapkan Risiko dan Peluang

a. Langkah-langkah pengendalian risiko dan peluang

b. Cara untuk :

1) Mengintegrasikan dan mengambil tindakan proses sistem manajemen mutu sehingga setiap proses telah teridentifikasi risikonya

2) Melakukan evaluasi keefektifan tindakan yang telah diambil dengan cara monitoring atau dilakukan audit

3) Tindakan yang diambil untuk menangani risiko dan peluang harus sesuai terhadap dampak kesesuaian produk dan jasa

B. Hasil Identifikasi Gap

Hasil perbandingan antara requirement ISO 9001:2015

klausul 6.1 dengan kondisi aktual, perbandingan antara $I S O$ 31000:2009 dengan kondisi aktual, dan perbandingan teori dan kondisi aktual menghasilkan gap, berikut ini hasil gap yang dilakukan:

1. Perusahaan harus melakukan penetapan isu-isu internal dan eksternal secara berkala

2. Perusahan harus melakukan pendokumentasian dari manajemen risiko perusahaan

3. Perusahaan mengintegrasikan manajemen risiko dengan sistem manajemen mutu

4. Perusahaan melakukan perencanaan dalam melakukan manajemen risiko

5. Perusahaan harus membuat langkah-langkah manajemen risiko 
6. Perusahaan harus melakukan evaluasi terhadap penanganan risiko

7. Perusahaan melakukan peninjauan terhadap sistem manajemen risiko.

Hasil dari requirement yang telah diintergasikan dan telah menghasilkan gap merupakan masukan untuk membuat perancangan proses menetapkan risiko dan peluang, sehingga pada proses tersebut telah memenuhi ISO 9001:2015 klausul 6.1, ISO 31000:2009, dan teori manajemen risiko.

\section{Proses Bisnis Menetapkan Risiko dan Peluang}

Dalam melakukan perancangan proses dilakukan penetapan urutan aktivitas didalam proses tersebut, kemudian ditentukan sumber daya sebagai penanggung jawab pada setiap aktivitas tersebut. Tabel I merupakan hasil rancangan urutan proses berdasarkan requirement.

TABEL I

PROSES BISNIS BERDASARKAN REQUIREMENT

\begin{tabular}{|c|l|l|}
\hline No. & \multicolumn{1}{|c|}{ Aktivitas } & \multicolumn{1}{|c|}{ Pemilik Proses } \\
\hline 1 & $\begin{array}{l}\text { Melakukan perencanan pelaksanaan manajemen } \\
\text { risiko perusahaan }\end{array}$ & $\begin{array}{l}\text { Direksi dan Bag.Quality } \\
\text { Control }\end{array}$ \\
\hline 2 & Melakukan koordinasi & $\begin{array}{l}\text { Direksi dan Unit Kerja } \\
\text { Terkait }\end{array}$ \\
\hline 3 & Menentukan konteks dan stakeholder & $\begin{array}{l}\text { Direksi dan Unit Kerja } \\
\text { Terkait }\end{array}$ \\
\hline 4 & Melakukan persiapan self assessment & Unit Kerja Terkait \\
\hline 5 & Melakukan self assessment risiko & Unit Kerja Terkait \\
\hline 6 & $\begin{array}{l}\text { Melakukan pengambilan keputusan dan } \\
\text { penanganan risiko }\end{array}$ & Unit Kerja Terkait \\
\hline 7 & Melakukan monitoring dan kaji ulang risiko & $\begin{array}{l}\text { Unit Kerja Terkait dan } \\
\text { Bag.Quality Control }\end{array}$ \\
\hline 8 & Membuat laporan hasil audit penanganan risiko & Unit Kerja Terkait \\
\hline 9 & Melakukan tinjauan manajemen risiko & $\begin{array}{l}\text { Direksi dan Unit Kerja } \\
\text { Terkait }\end{array}$ \\
\hline 10 & Melakukan perbaikan & $\begin{array}{l}\text { Direksi dan Bag.Quality } \\
\text { Control }\end{array}$ \\
\hline
\end{tabular}

Kemudian menentukan kriteria proses sebagai indikator apakah proses tersebut berjalan baik atau tidak. Kriteria pada proses tindakan untuk menangani risiko dan peluang adalah efektivitas penanganan risiko pada setiap proses yang ditangani. Tabel II merupakan kriteria pada proses.

TABEL II

KRITERIA PROSES

\begin{tabular}{|c|c|c|c|}
\hline Kinerja & Indikator Kinerja & Kriteria & $\begin{array}{c}\text { Frekuensi } \\
\text { Pengukuran }\end{array}$ \\
\hline $\begin{array}{c}\text { Efektivitas } \\
\text { penanganan risiko } \\
\text { pada setiap proses } \\
\text { yang ditangani }\end{array}$ & $\begin{array}{c}\text { Ep=(Jumlah penanganan dengan } \\
\text { hasil efektif/Jumlah proses yang } \\
\text { ditangani) } \times 100 \%\end{array}$ & $\mathrm{EP}>90 \%$ & 6 bulan sekali \\
\hline $\begin{array}{c}\text { Penerapan } \\
\text { manajemen risiko } \\
\text { di setiap unit }\end{array}$ & $\begin{array}{c}\mathrm{P}=(\text { Jumlah unit yang menangani } \\
\text { risiko/Jumlah unit di } \\
\text { perusahaan }) \times 100 \%\end{array}$ & $\mathrm{P}=100 \%$ & 6 bulan sekali \\
\hline
\end{tabular}

D. Hasil Rancangan Proses dengan Melakukan Perbaikan Menggunakan Metode Business Process Improvement

Pada proses menetapkan risiko dan peluang dilakukan perbaikan menggunakan metode BPI. Berikut ini tools berdasarkan improvement technique yang digunakan pada saat memperbaiki proses menetapkan risiko dan peluang:

\section{Automation}

Tool ini digunakan pada aktivitas ke-5 pada proses menetapkan risiko dan peluang yang telah di rancang, yaitu ketika melakukan assessment risiko. Pada aktivitas ke-5 melakukan identifikasi risiko, nilai risiko, dan juga tindakannya secara manual. Untuk menghemat biaya perusahaan dalam pengeluaran kertas, maka sebaiknya perusahaan menggunakan bantuan sistem informasi. Aplikasi berbasis web yaitu Joget Workflow merupakan salah satu solusi yang bisa diterapkan perusahaan, dimana setiap unit perusahaan akan melakukan pengisian melalui form yang ada pada aplikasi tersebut. Dengan menggunakan aplikasi berbasis web akan memudahkan perusahaan dalam melakukan input data, kemudian perusahaan juga bisa melakukan update data jika terdapat perubahan atau penambahan.Fitur lainnya adalah terdapat laporan mengenai risiko yang telah di input berbentuk diagram, sehingga akan memudahkan perusahaan dalam melakukan pelaporan risiko yang berada di unit masing-masing.Keuntungan lainnya ialah dokumen tidak mudah hilang dan juga tercecer, sehingga pendokumentasian dapat terstruktur secara rapi.

\section{Simplifying}

Perbaikan yang dilakukan dengan tool ini yaitu pada aktivtas ke-2, ke-3, ke-5, dan ke-6 pada proses menetapkan risiko dan peluang yang telah di rancang, karena pada aktivitas tersebut terdapat penggunaan form dan terdapat aktivitas yang memiliki penanggung jawab yang sama. Sehingga diusulkan untuk menggunakan form yang dirancang yang ringkas agar mengurangi kompleksitas dari penggunaan form tersebut. Selain itu untuk aktivitas yang memiliki penanggung jawab yang sama, aktivitas tersebut digabungkan sehingga terlihat ringkas.

E. Hasil Rancangan Proses dengan Kesesuian Gap Analysis

Perancangan proses menetapkan risiko dan peluang dibuat berdasarkan gap analysis. Gap analysis tersebut yaitu membandingkan antara kondisi aktual dengan requirement ISO 9001:2015 klausl 6.1, requirement ISO 31000:2009, dan requirement manajemen risiko berdasarkan teori. Dari perbandingan tersebut terdapat tujuh gap, sehingga proses yang dirancang berdasarkan tujuh gap tersebut. Untuk mengetahui kesesuaian hasil rancangan yang telah dibuat, maka dilakukan pemeriksaan kesesuaian hasil rancangan proses dengan hasil gap analysis. Tabel III merupakan kesesuaian gap analysis dengan hasil rancangan proses.

F. Rancangan Standard Operating Procedure Menetapkan Risiko dan Peluang

Hasil rancangan standard operating procedure menetapkan risiko dan peluang merupakan output yang dihasilkan setelah dilakukan perancangan proses menetapkan risiko dan peluang. Proses menetapkan risiko dan peluang didokumentasikan menjadi sebuah standard operating procedure yang berguna sebagai langkah-langkah atau panduan 
perusahaan untuk melakukan manajemen risiko perusahaan. Standard Operating Procedure yang telah dibuat telah memenuhi requirement ISO 9001:2015 klausul 6.1, requirement ISO 31000:2009, dan requirement teori manajemen risiko.Hasil standard operating procedure telah diverifikasi oleh perusahaan, hal ini menunjukkan bahwa perusahaan telah menyetujui dan aktivitas yang ada di dalam prosedur tersebut bisa diimplementasikan oleh perusahaan. Prosedur menetapkan risiko dan peluang telah dilampirkan pada lembar Lampiran 1.

TABEL III

\begin{tabular}{|l|l|}
\hline \multicolumn{1}{|c|}{ KESESUAIAN Analysis } & \multicolumn{1}{|c|}{ Hasil Rancangan Proses } \\
\hline $\begin{array}{l}\text { Penetapan isu internal dan isu } \\
\text { eksternal secara berkala }\end{array}$ & $\begin{array}{l}\text { Pada hasil rancangan melakukan } \\
\text { penetapan di rapat manajemen } \\
\text { perusahaan }\end{array}$ \\
\hline $\begin{array}{l}\text { Membuat dokumentasi isu } \\
\text { internal dan eksternal }\end{array}$ & $\begin{array}{l}\text { Dihasilkan form sebagai dokumentasi isu } \\
\text { internal dan eksternal }\end{array}$ \\
\hline $\begin{array}{l}\text { Penilaian risiko dilakukan } \\
\text { ditiap proses }\end{array}$ & $\begin{array}{l}\text { Hasil rancangan terdapat penilaian risiko } \\
\text { di setiap unit kerja perusahaan }\end{array}$ \\
\hline $\begin{array}{l}\text { Melakukan perencanaan } \\
\text { manajemen risiko }\end{array}$ & $\begin{array}{l}\text { Pada hasil rancangan terdapat aktivitas } \\
\text { melakukan perencanaan pelaksanaan } \\
\text { manajemen risiko perusahaan untuk } \\
\text { mengetahui timeline yang akan } \\
\text { diimplementasikan }\end{array}$ \\
\hline $\begin{array}{l}\text { Mendokumentasikan } \\
\text { langkah-langkah Menetapkan } \\
\text { risiko dan peluang }\end{array}$ & $\begin{array}{l}\text { Didokumentasikan dalam bentuk SOP } \\
\text { menetapkan risiko dan peluang }\end{array}$ \\
\hline $\begin{array}{l}\text { Evaluasi penanganan risiko } \\
\text { secara berkala }\end{array}$ & $\begin{array}{l}\text { Evaluasi dilakukan setiap 6 bulan sekali } \\
\text { yaitu pada saat monitoring dan review } \\
\text { tindakan terhadap risiko }\end{array}$ \\
\hline $\begin{array}{l}\text { Melakukan tinjauan } \\
\text { manajemen risiko secara } \\
\text { berkala }\end{array}$ & $\begin{array}{l}\text { Diakhir aktivitas terdapat peninjauan } \\
\text { terhadap implementasi yang dilakukan } \\
\text { perusahaan, aktivitas ini dilakukan setiap } \\
\text { akhir tahun }\end{array}$ \\
\hline
\end{tabular}

\section{G. Hasil Risk Management Application}

Risk management application merupakan sebuah alat bantu untuk perusahaan dalam hal mendokumentasikan manajemen risikonya. Aplikasi ini dibuat dengan software Joget Workflow. Aplikasi ini memudahkan pengguna untuk melakukan penilaian pada risiko dan pada saat melakukan monitoring risiko. Pengguna juga bisa membuat laporan dengan menggunakan aplikasi ini, sehingga aplikasi ini merupakan automatisasi dari aktivitas penilaian hingga pelaporan pengelolaan risiko. Terdapat tampilan dari aplikasi risk management yang telah dilampirkan pada Lampiran 2.

\section{KESIMPULAN}

Pada penelitian di CV XYZ didapatkan beberapa gap berdasarkan requirement ISO 9001:2015 klausul 6.1, requirement ISO 31000:2009, dan requirement teori manajemen risiko, selain itu merancang proses menetapkan risiko dan peluang sebagai acuan perusahaan dalam menangani risiko. Proses yang telah dirancang tersebut kemudian didokumentasikan menjadi SOP Menetapkan risiko dan peluang sesuai dengan requirement pada ISO 9001:2015, ISO 31000:2009, dan requirement teori manajemen risiko.
Berdasarkan analisis tersebut dapat ditarik kesimpulan sebagai berikut:

1. Berdasarkan hasil gap yang mengacu pada requriement ISO 9001:2015 klausul 6.1, requriement ISO 31000:2009, dan requirement teori manajemen risiko, didapatkan bahwa dalam mengidentifikasi konteks organisasi dan stakeholder harus dilakukan secara berkala karena kondisi tersebut dapat berubah-ubah. Kemudian dalam menerapakan proses manajemen risiko, perusahaan tidak bisa hanya menerapkan di satu proses saja. Hal ini dikarenakan menurut ISO 9001:2015 klausul 6.1, risiko dan peluang harus dipertimbangkan untuk setiap proses di dalam perusahaan. Setelah dilakukan pelaksanaan manajemen risiko perusahaan harus melakukan tinjauan manajemen risiko sebagai bahan evaluasi dalam pelaksanaan manajemen risiko perusahaan, sehingga proses menetapkan risiko dan peluang diperbaiki secara terus menerus.

2. Hasil analisis gap digunakan sebagai input dalam melakukan perancangan proses menetapkan risiko dan peluang. Sebelum melakukan perancangan, dilakukan penentuan input dan ouput, urutan proses dan penanggung jawab, dan kriteria dari proses tersebut. Pada proses menetapkan risiko dan peluang meliputi beberapa aktvitas seperti, perencanaan manajemen risiko perusahaan, melakukan self assessment unit kerja, melakukan pengambilan keputusan untuk penanganan risiko, monitoring hasil penanganan risiko hingga melakukan tinjauan manajemen risiko perusahaan.

3. Setelah dilakukan perancangan kemudian dilakukan perbaikan perancangan dengan menggunakan metode business process improvement, yaitu dengan menggunakan cara apply improvement technique sehingga proses tersebut menjadi lebih efektif dan efisien.

4. Hasil rancangan proses menetapkan risiko dan peluang yang dibuat telah sesuai dengan persyaratan pada ISO 9001:2009 klausul 6.1 dengan melalui beberapa pendekatan ISO 31000:2009 dan teori manajemen risiko agar proses tersebut bisa diterapkan di CV XYZ. Kemudian rancangan proses tersebut didokumentasikan berupa standard operating procedure sebagai informasi terdokumentasi perusahaan.

5. Selain rancangan proses yang didokumentasikan menjadi SOP, terdapat software Joget Workflow berupa aplikasi Risk Management Application untuk mendukung proses menetapkan risiko dan peluang.

\section{DAFTAR PUSTAKA}

[1] Badan Pusat Statistik, "Jumlah Perusahaan Industri Mikro dan Kecil Menurut Provinsi,2013-2015," 8 Oktober 2016. [Online]. Available: https://www.bps.go.id/linkTableDinamis/view/id/1004.

[2] J. Priede, "Implementation of Quality Management System ISO 9001 in the World and Its Strategic 
Necessity," Procedia - Social and Behavioral Sciences, vol. 58, pp. 1466-1475, 2012.

[3] L. Miguel, "ISO 9001 Quality Management Systems through the Lens," Quality Access to Success, vol. 16, pp. 54-59, 2015.

[4] D. V. B. Durai Anand Kumar, "A Study on ISO 9001 Quality Management System," Global Journal of Management and Business Research, vol. 1, no. 9, pp. 43-49, 2011.

[5] J. PLURA, "CONTINUAL IMPROVEMENT WITHIN THE QUALITY," KVALITA INOVÁCIA PROSPERITA, vol. 4, pp. 13-22, 2000.

[6] B. S. Nasional, "Sistem Manajemen Mutu ISO 9001:2015," 2015.

[7] S. Hery, Manajemen Risiko Bisnis, Jakarta: PT Grasindo, 2015.

[8] The University of Adelaide, "Risk Management Framework," Annals of Physics, p. 258, 2009.

[9] P. Hopkin, Fundamental Of Risk Management, Kogan Page Limited, 2010.
[10] B. Andersen, Business Process Improvement Toolbox Second Edition, Milwaukee: ASQ Quality Press, 2007.

[11] Khairunnisa, S., Widaningrum, S., \& Lalu, H. (2016). PERANCANGAN SOP AUDIT INTERNAL BERDASARKAN INTEGRASI ISO 9001:2015 (KLAUSUL 9.2) DAN ISO 14001:2015 (KLAUSUL 9.2) DENGAN MEMPERTIMBANGKAN RISIKO MENGGUNAKAN METODE BENCHMARK DI CV XYZ. Jurnal Rekayasa Sistem \& Industri (JRSI), 3(02), $38-46$.

[12] Farhana, N., Widaningrum, S., \& Lalu, H. (2016). PERANCANGAN SOP MANAGEMENT REVIEW BERDASARKAN INTEGRASI ISO 9001:2015 (KLAUSUL 9.3) DAN ISO 14001:2015 (KLAUSUL 9.3) DENGAN MEMPERTIMBANGKAN RISIKO MENGGUNAKAN METODE BENCHMARK DI CV XYZ. Jurnal Rekayasa Sistem \& Industri (JRSI), 3(03), $39-47$. 
Lampiran 1

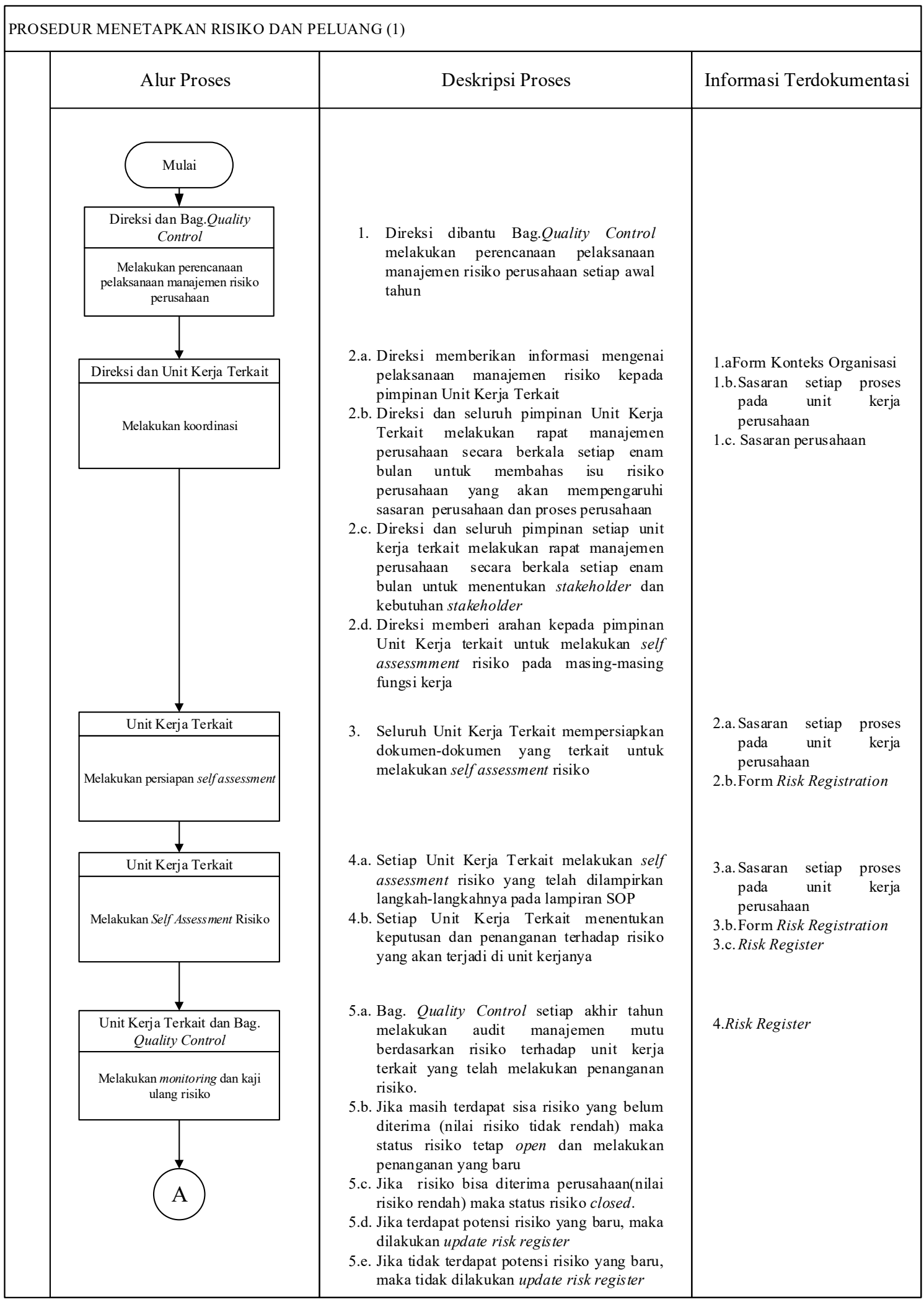




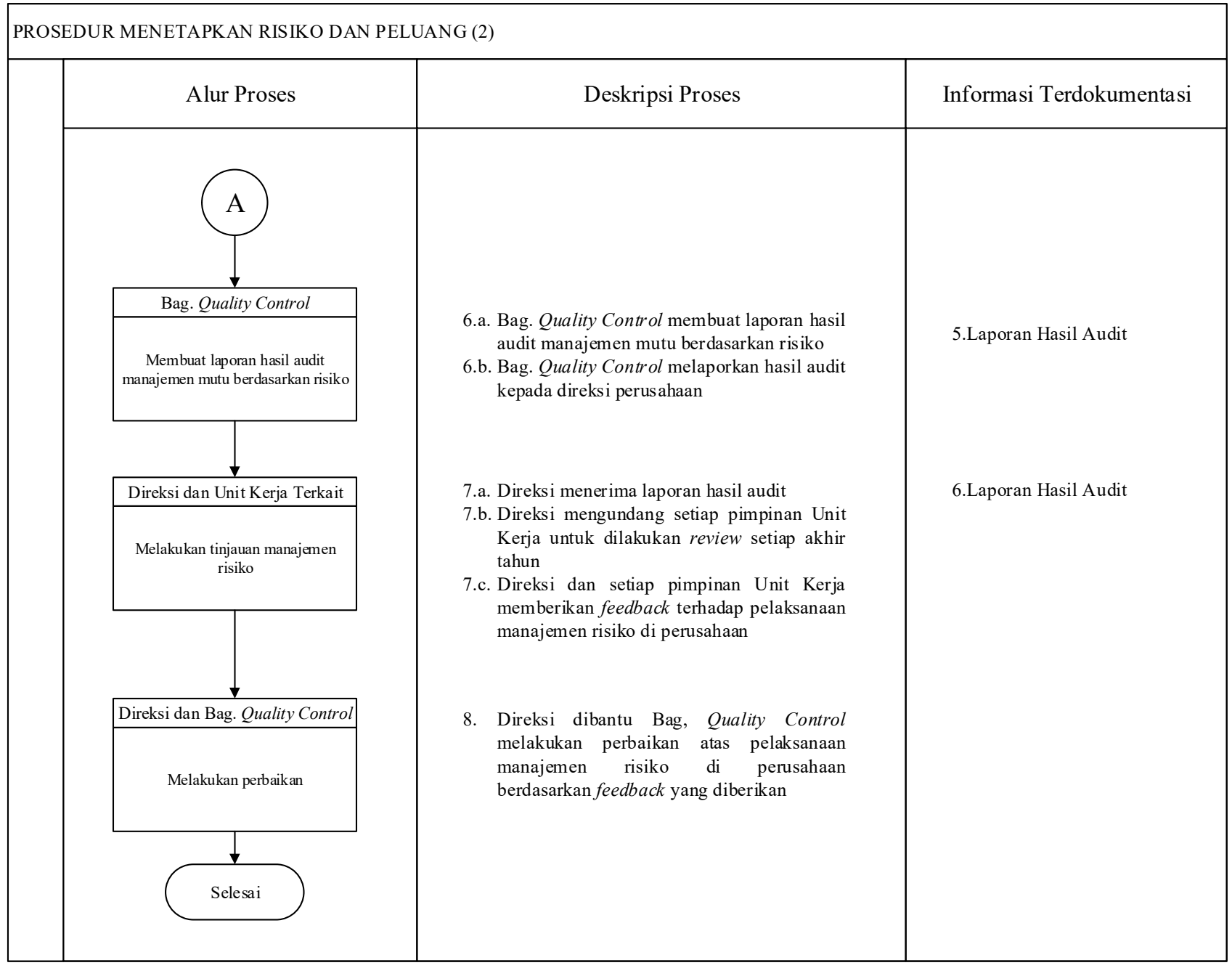


Lampiran 2

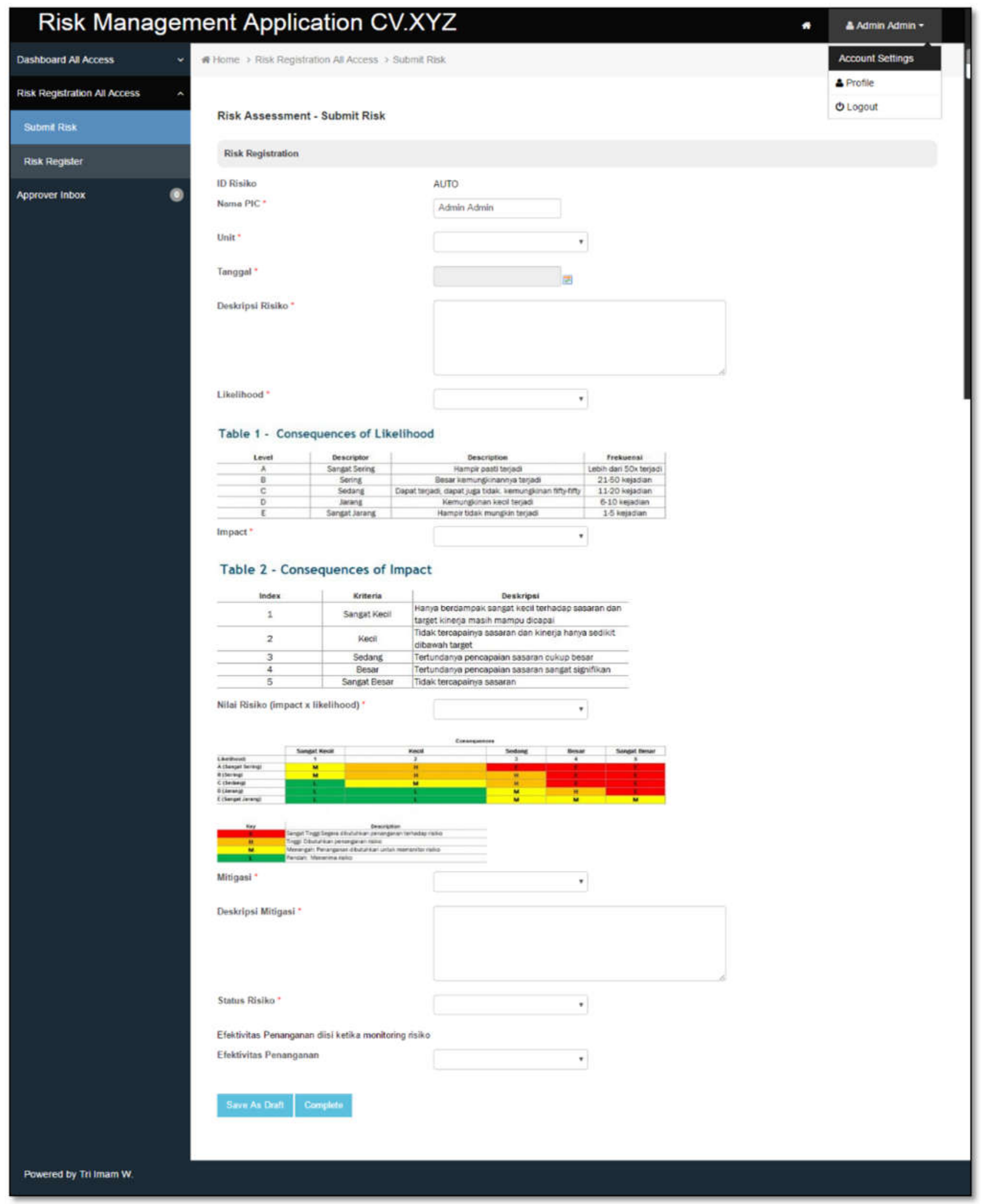

Perancangan Proses Menetapkan Risiko dan Peluang Berdasarkan ISO 9001:2015 Klausul 6.1 Dengan Pendekatan ISO 31000:2009 Menggunakan Metode Business Process Improvement di CV XYZ 

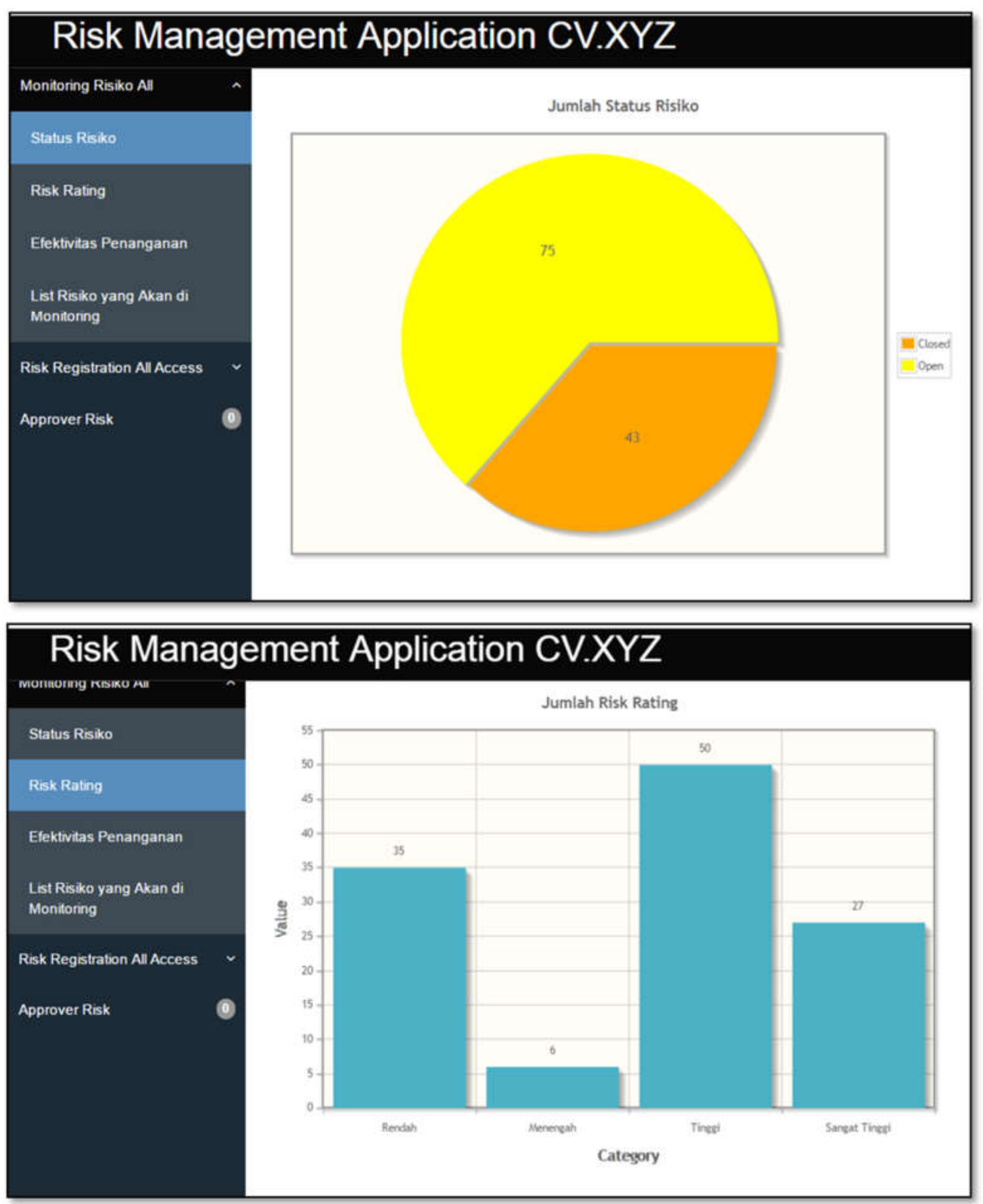